\title{
New Narrow-Band Luminescence Using Lanthanide Coordination Compounds for Light-Emitting Diodes
}

\author{
Seo Young IM ${ }^{\dagger a)}$, Da Hyeon GO ${ }^{\dagger}$, Jeong Gon $\mathrm{RYU}^{\dagger}$, and Young Sic $\mathrm{KIM}^{\dagger}$, Nonmembers
}

\begin{abstract}
SUMMARY For ternary system, both anionic carboxylate ligand, namely, 4,4'-oxybis(benzoic acid) $\left(\mathrm{H}_{2} \mathrm{Oba}\right)$ and different auxiliary ligand, namely, 1,10-phenanthroline(Phen), pyrazino[2,3-f][1,10]phenanthroline (dpq) and 1H-imidazole[2,3-f][1,10]phenanthroline(IP) have been designed and employed for the construction of a series of lanthanide compounds $\left(\mathrm{Tb}^{3+}, \mathrm{Eu}^{3+}\right)$. The results of photoluminescence spectra of the compounds show the different optimal excitation spectra that make it closer to UV/Blue range.

key words: LED, high (wide) color gamut, new phosphor, organicinorganic hybrid, narrow emission
\end{abstract}

\section{Introduction}

Solid state lighting based on white light emitting diodes (LED) are well known for display devices and the inorganic phosphors have a great attention for their useful advantages in the devices [1]. Inorganic phosphors are exact materials for blue-chip excitation with intensive luminescence and high reliability. However, the conventional phosphors for LEDs have been difficult to make high color gamut because of the limitation to the ability of color reproduction and have re-absorption due to the wide band width [2]. Furthermore, the synthesis conditions of the phosphors need high temperature, pressure, etc [3]. In recent years, great efforts and time have been studying in making the successful devices or materials to overcome these problems. There has been a growing interest in the luminescence properties of lanthanide coordination polymers because of their potential use such as catalysis [4], luminescence [5], magnetism [6] and gas storage [7]. Especially, $\mathrm{Eu}^{3+}, \mathrm{Tb}^{3+}$ and $\mathrm{Sm}^{3+}$ ions have excellent luminescence properties, but their excitation bands are weak and narrow. In order to enhance excitation spectrum, lanthanide $\left(\mathrm{Ln}^{3+}\right)$ ions are usually coordinated with ligands that have broad intense excitation bands and can redshift of excitation spectrum to UV/Blue range [8]. In these systems intense ion luminescence originates from the intramolecular energy transfer through the excited state of the ligand to the emitting level of the lanthanide central ions that give a sharp narrow spectral character [9]. In this study, we introduce a new lanthanide coordination compounds composing of lanthanide ions $\left(\mathrm{Ln}^{3+}=\mathrm{Eu}^{3+}, \mathrm{Tb}^{3+}\right)$ and specific organic ligands to exhibit sharp and narrow red and green

Manuscript received March 7, 2017.

Manuscript revised June 6, 2017.

${ }^{\dagger}$ The authors are with R\&D Business Labs., Hyosung Corporation, 74, Simin-daero, Dongan-gu, Anyang-si, Gyeonggi-do, Korea.

a)E-mail: hellosy@hyosung.com

DOI: $10.1587 /$ transele.E100.C.1021 colored emission, respectively, by near UV chip (400nm) for WLEDs. We also demonstrate that this approach showed the possibility to be the ideal phosphors for LEDs.

\section{Experimental}

Materials. Chemicals were purchased from Sigma Aldrich. All chemicals used without further purification

\subsection{Synthesis of $[\mathrm{Tb}(\mathrm{Phen})(\mathrm{oba})($ Hoba $)] n$}

(Compound 1, $\mathrm{H}_{2} \mathbf{o b a}=4,4$ '-oxybis(benzoic acid)

A mixed solution was prepared by dissolving $\mathrm{Tb}\left(\mathrm{NO}_{3}\right)_{3} \cdot 5 \mathrm{H}_{2} \mathrm{O}(0.2 \mathrm{mmol}), \quad \mathrm{H}_{2} \mathbf{o b a}(0.3 \mathrm{mmol}) \quad$ and Phen $(0.5 \mathrm{mmol})$ in deionized water and stirred for $20 \mathrm{~min}$ in the air. The mixture was transferred into $50 \mathrm{~mL}$ Teflonlined reactor and kept at $160^{\circ} \mathrm{C}$ for $40 \mathrm{~h}$, then cooled to room temperature. The product showed light yellow color under natural light was obtain after washed with ethanol and dried at $70^{\circ} \mathrm{C}$ for $3 \mathrm{~h}$ in an oven.

\subsection{Synthesis of $[\mathrm{Tb}(\mathrm{dpq})(\mathrm{oba})($ Hoba $)] n(2)$}

Compound 2 was prepared in the same way as that of (1) except that adding $0.3 \mathrm{mmol}$ of $\mathrm{dpq}$.

\subsection{Synthesis of $[(\mathrm{Tb})(\mathrm{IP})(\mathrm{oba})(\mathrm{Hoba})] \mathrm{n}(3)$}

Compound 3 was prepared in the same way as that of (1) except that adding $0.3 \mathrm{mmol}$ of IP.

\subsection{Synthesis of $[(\mathrm{Eu})(\mathrm{Phen})(\mathrm{oba})(\mathrm{Hoba})] \mathrm{n}(4)$}

A mixture of $\mathrm{Eu}\left(\mathrm{NO}_{3}\right)_{3} \cdot 5 \mathrm{H}_{2} \mathrm{O}(0.5 \mathrm{mmol}), \mathrm{H}_{2}$ oba $(1 \mathrm{mmol})$, Phen $(0.5 \mathrm{mmol})$ and water $(50 \mathrm{ml})$ was stirred for $20 \mathrm{~min}$ in the air. The mixture was transferred into $50 \mathrm{~mL}$ Teflon-lined reactor and kept at $150^{\circ} \mathrm{C}$ for $50 \mathrm{~h}$, then cooled to room temperature. The product showed yellow color under natural light was obtained after washed with ethanol an dried at $70^{\circ} \mathrm{C}$ for $3 \mathrm{~h}$ in an oven.

\subsection{Synthesis of [Eu(dpq)(oba)(Hoba)]n (5)}

Compound 5 was prepared in the same way as that of (1) except that adding $0.5 \mathrm{mmol}$ of dpq. 


\subsection{Fabrication of a Simple LED Assembly}

A red LED was prepared by dripping the compound 5 of $5 \mathrm{wt} \%$ with silicon encapsulment on a commercially available LED chip ( $\lambda$ ex $=400 \mathrm{~nm})$. The LEDs were evaluated at $3.0 \mathrm{~V}$ with currents of $60 \mathrm{~mA}$.

\subsection{Characterization}

The solid-state luminescent spectra were obtained with a DARSA PRO-5200 SYSTEM (Xe lamp, 500W).

\section{Result and Discussion}

\subsection{Photophysical Properties of Green Compounds 1-3}

The luminescence excitation and emission spectra of compounds 1-3 that are solid powder samples are shown in Fig. 1. Figure 1(a) shows that the emission spectra of compound 1-3 upon excitation at $400 \mathrm{~nm}$ consist of sharp lines within the $450-700 \mathrm{~nm}$ range. These spectra are composed of the typical $\mathrm{Tb}^{3+}$ green emission, corresponding to ${ }^{5} \mathrm{D}_{4} \rightarrow{ }^{7} \mathrm{~F}_{J}(\mathrm{~J}=0-6)$ levels of $\mathrm{Tb}^{3+}$ ions [10]. The main emission peak at $545 \mathrm{~nm}$ is due to the ${ }^{5} \mathrm{D}_{4} \rightarrow{ }^{7} \mathrm{~F}_{5}$ transitions of $\mathrm{Tb}^{3+}$; the peak at $487 \mathrm{~nm}$ is attributed to ${ }^{5} \mathrm{D}_{4} \rightarrow{ }^{7} \mathrm{~F}_{6}$ transitions; and the peaks at 580 and $620 \mathrm{~nm}$ are due to the ${ }^{5} \mathrm{D}_{4} \rightarrow{ }^{7} \mathrm{~F}_{4}$ and ${ }^{5} \mathrm{D}_{4} \rightarrow{ }^{7} \mathrm{~F}_{3}$ transitions of $\mathrm{Tb}^{3+}$. Figure 1 (b) shows the excitation spectrum of the compound $1-3$ recorded at $298 \mathrm{~K}$ in the $300-450 \mathrm{~nm}$ range by monitoring the $\mathrm{Tb}^{3+}$ emission from the ${ }^{5} \mathrm{D}_{4} \rightarrow{ }^{7} \mathrm{~F}_{5}$ transition at around $545 \mathrm{~nm}$, which matches well with near UV chip of the $400 \mathrm{~nm}$. Interestingly, the excitation spectra of the compounds 1-3 have an obvious red-shift. The excitation spectra of compound 1-3 exhibit a broad band between 300 and $400 \mathrm{~nm}$ which is definitely originated from the different coordination environments caused by the different auxiliary ligand of compounds. The compounds 1-2 have weak luminescence upon excitation at 400nm because of barely excitation spectra around near UV range, but the compound 3 exhibits an intense, characteristic green $\mathrm{Tb}^{3+}$ emission. General phosphors with lanthanide ions formed small absorption regions because of forbidden character of $\mathrm{f}-\mathrm{f}$ transition. However, a slight red shift is discernible in the optimal excitation of the compound 1-3 that is from 300 to $400 \mathrm{~nm}$, which could be ascribed to the perturbation induced by $\mathrm{Ln}^{3+}$ coordination.

For ternary systems, both anionic and neutral ligands can serve as the antenna effect to harvest and transfer energy to $\mathrm{Ln}^{3+}$. They contain two distinct coordination domains, one from anionic carboxyl group which is called main ligand and another from neutral phen-based ligands domain which is called auxiliary ligand.

Commonly, an anionic ligand have to suitable triplet energy to meet Latvia's empirical rule that is an optimal ligand-to-metal energy transfer process for $\mathrm{Tb}^{3+}$ and $\mathrm{Eu}^{3+}$ about $\Delta \mathrm{E}\left(\mathrm{T}^{-5} \mathrm{D}_{\mathrm{j}}\right)$ in gate $2100-4500 \mathrm{~cm}^{-1}[11]$, and (a)

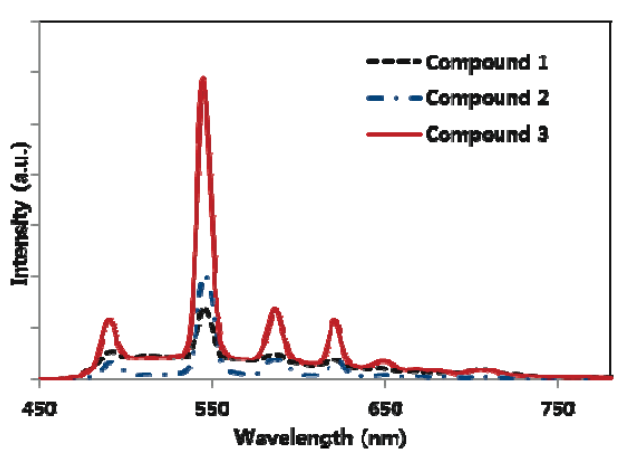

(b)

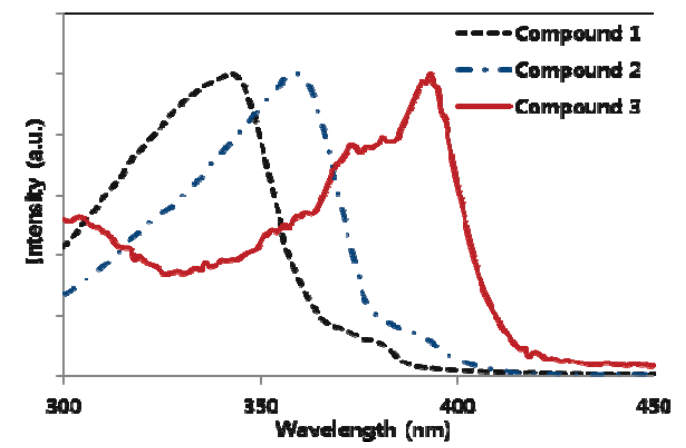

Fig. 1 Compounds 1-3 of emission spectra (excited at $400 \mathrm{~nm}$ ) for (a) and normalized excitation spectra for (b) (both monitored at $545 \mathrm{~nm}$ )

an auxiliary ligand should have suitable excited levels to support energy transfer to anionic ligand and $\mathrm{Ln}^{3+}$. The singlet energy $\left({ }^{1} \pi \pi^{*}\right)$ levels of phen $\left(29,000 \mathrm{~cm}^{-1}\right)$, $\operatorname{dpq}\left(28,000 \mathrm{~cm}^{-1}\right)$, and triplet energy $\left({ }^{3} \pi \pi^{*}\right)$ levels of phen $\left(22,100 \mathrm{~cm}^{-1}\right), \mathrm{dpq}\left(24,000 \mathrm{~cm}^{-1}\right)$ were found from the literatures. Based on this experimental results, it is suggested that the red shifted excitation of compound 1-3 originated from the $\pi-\pi^{*}$ electronic transition of auxiliary ligand that can easily be extended conjugated system. The different auxiliary ligands can make it to relocate the energy from organic linkers to metals and the triplet energy level of auxiliary ligands are obviously higher than the ${ }^{5} \mathrm{D}_{4}$ level $\left(21000 \mathrm{~cm}^{-1}\right)$ of $\mathrm{Tb}^{3+}$, and its energy gap $\Delta \mathrm{E}\left({ }^{3} \pi \pi^{*}-{ }^{5} \mathrm{D}_{4}\right)$ between ligand and metal-centered levels is too high to allow an effective back energy transfer. In this case, the ligand in coordination polymers absorbs the light and transfers the energy to the lanthanide ions. Therefore, the compounds have wide excitation bands with sharp emission. This optical property in the compounds is so-called antenna effect. Both emission spectra show enhanced bright and narrow green light at the same wavelength at about $545 \mathrm{~nm}$, but both bands can be distinguished in the intensity of luminescence and excitation spectra of the materials, 1 which contains Phen described the excitation band with a maximum at about 340nm and the main excitation peak of 2 is about $365 \mathrm{~nm}$ and of 3 is about $400 \mathrm{~nm}$ (Fig. 1 (b)). The different excitation spectra are attributed to the energy differences from the auxiliary ligands. High conjugated ligands such as dpq, IP make the main peak of excitation shift to the longer 
(a)

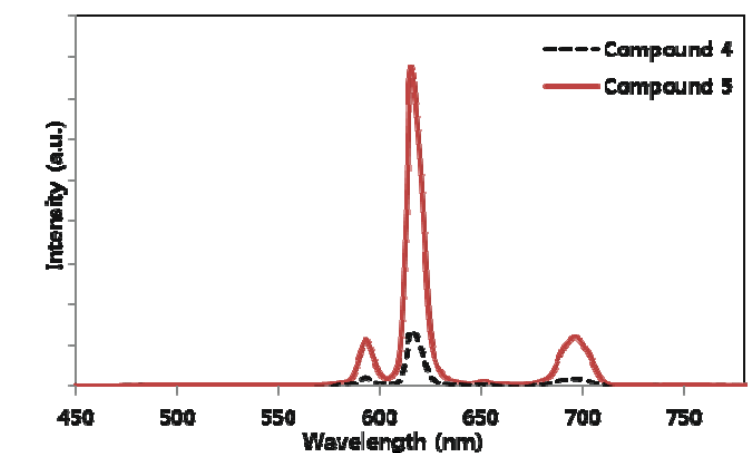

(b)

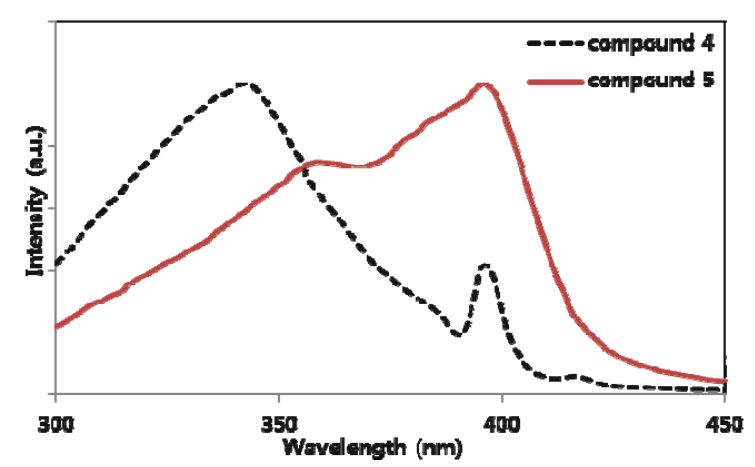

Fig. 2 Compounds 4-5 of emission spectra (excited at $400 \mathrm{~nm}$ ) for (a) and normalized excitation spectra (both monitored at $615 \mathrm{~nm}$ ) for (b)

wavelength.

\subsection{Photophysical Properties of Red Compounds 4-5}

Compound 4 composed of 4,4'-oxybis(benzoic acid), Eu ${ }^{3+}$ ion and 1,10-phenanthroline by method reported previously and Compound 5 are easily synthesized by modified the method of compound 4 [12]. The photoluminescence properties of the solid powder samples of compound 4-5 were investigated by the condition with compound 1-3 but the results are not the same as that of green compounds. The materials show various luminescent phenomena derived from chemical building blocks such as ligands and metals or interactions between components [13]. Figure 2 (a) shows that the emission spectra of compound 4-5 upon excitation at $400 \mathrm{~nm}$ appear in the range of 570-705 $\mathrm{nm}$ with sharp lines. It displays intensity red luminescence and the characteristic f-f transition of Eu(III) ions that have the ${ }^{5} \mathrm{D}_{0} \rightarrow{ }^{7} \mathrm{~F}_{\mathrm{J}}(\mathrm{J}=0$ 4) transitions. The sharp emission at $613 \mathrm{~nm}$ of the $\mathrm{Eu}^{3+}$ ion from ${ }^{5} \mathrm{D}_{0} \rightarrow{ }^{7} \mathrm{~F}_{2}$ was observed accompanied by weak emission corresponding to emissions at 579, 594, and $643 \mathrm{~nm}$ that are attributed to ${ }^{5} \mathrm{D}_{0} \rightarrow{ }^{7} \mathrm{~F}_{0},{ }^{5} \mathrm{D}_{0} \rightarrow{ }^{7} \mathrm{~F}_{3}$, and ${ }^{5} \mathrm{D}_{0} \rightarrow{ }^{7} \mathrm{~F}_{4}$ respectively [14]. According to the above experimental results, the auxiliary ligands of phen and dpq have higher triplet energy level that is over $22000 \mathrm{~cm}^{-1}$ than the ${ }^{5} \mathrm{D}_{0}$ level $\left(17000 \mathrm{~cm}^{-1}\right)$ of $\mathrm{Eu}^{3+}$, which is in the range proposed for optical ligand-to-Eu ${ }^{3+}$ energy transfer. The quantum yield of the compound, evaluated under $400 \mathrm{~nm}$ at room
Table 1 Important optical parameters of compound 5

\begin{tabular}{|l|l|l|l|}
\hline & $\begin{array}{l}\text { Excitation } \\
\text { main peak }\end{array}$ & $\begin{array}{l}\text { Emission } \\
\text { main peak }\end{array}$ & QuantumYield \\
\hline Compound 5 & $400 \mathrm{~nm}$ & $613 \mathrm{~nm}$ & $22 \%$ \\
\hline
\end{tabular}

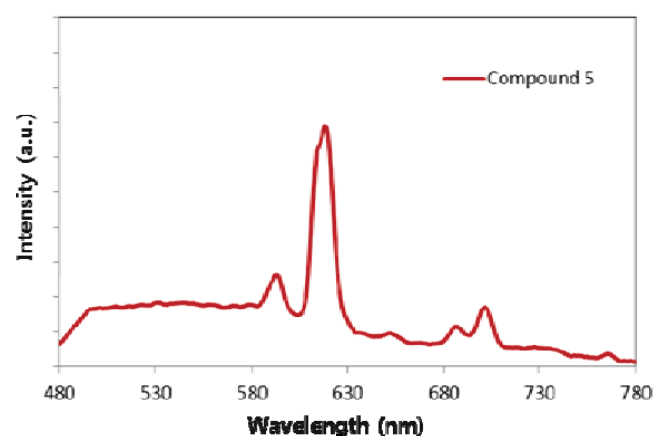

Fig. 3 Emission spectrum of compound 5 (excited at 450nm)

temperature, was $22 \%$, which is lower than inorganic phosphors, but our group has found that quantum yield can be improved by using modified ligands [11].

Figure 2 (b) shows that the excitation spectra of compound 4-5 exhibit broad bands from 300 to $450 \mathrm{~nm}$ which is attributable to the auxiliary ligands of aromatic moiety. Compared to compound 4 under $300-400 \mathrm{~nm}$ excitation, compound 5 has the broad band with a maximum at 400nm. (Fig. 2 (b)). Obviously, the spectrum of coumpound 5 is more red-shifted due to the energy level of auxiliary ligands.

The different singlet energy level of auxiliary ligands between phen $\left(29,000 \mathrm{~cm}^{-1}\right)$ and $\operatorname{dpq}\left(28,000 \mathrm{~cm}^{-1}\right)$ made it near-UV excitation and it can become a good candidate for blue LED. Figure 3 shows that the emission spectra of compound 5 upon excitation at $450 \mathrm{~nm}$. The research is still continued to shift the excitation range from near UV region to $450 \mathrm{~nm}$ used in blue LEDs.

\subsection{Fabrication and Performance of LED of Compounds 5}

To evaluate the PKG device fabrication of LEDs of compound 5, we made red LEDs by combining UV chips (400nm) and Compound 5. The PL spectrum of compound exhibits emission maxima at $613 \mathrm{~nm}$. When we collected the brightness and PL spectra of the LEDs under multiple weights $(\%)$ of $5 \mathrm{wt} \%, 10 \mathrm{wt} \%$ and $15 \mathrm{wt} \%$, the compound had $(0.262,0.088),(0.405,0.188)$ and $(0.485,0.250)$, representatively, marked in CIE 1931. The color of packages shifts to red when changing weights of compound. However, at $\mathrm{Cx}$ of compound, the color shifts less towards red, because the portion of UV chip light is dominant. Photographs and spectrum of the fabricated LED, which are $5 \mathrm{wt} \%$ compound, are shown in Fig. 4.

\section{Conclusion}

We have developed Organic-inorganic hybrid materials 


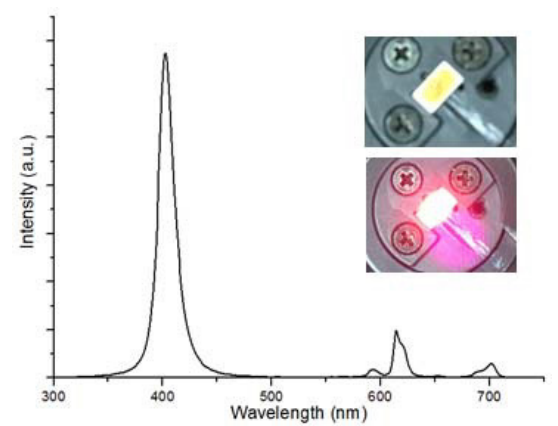

Fig. 4 Photoluminescent (PL) spectrum of $5 \mathrm{wt} \%$ compound under $60 \mathrm{~mA}$ drive current a.u., arbitrary units

from metal nitrates, auxiliary ligands and main ligands by hydrothermal methods. The Materials have narrow photoluminescence to protect re-absorption. Furthermore, Preparing the LEDs with purchasable UVLED chips and silicon encapsulant showed its potential for use as luminescent display material. We are certain that we can also fabricate the white LEDs with the developed red and green compounds in a well-controlled manner. We found that we can shift the excitation spectrum. We are under study about shifting the excitation from near UV region to blue $(450 \mathrm{~nm})$ by changing the ligands or metals.

\section{References}

[1] R.-J. Xie, N. Hirosaki, Y. Li, and T. Takeda, "Rare-Earth Activated Nitride Phosphors: Synthesis, Luminescence and Applications," Materials, vol.3, no.6, pp.3777-3793, 2010.

[2] Y. Hu, W. Zhuang, H. Ye, S. Zhang, Y. Fang, and X. Huang, "Preparation and Luminescent Properties of $\left(\mathrm{Ca}_{1 \mathrm{x}}, \mathrm{Sr}_{\mathrm{x}}\right) \mathrm{S}: \mathrm{Eu}^{2+}$ Red-Emitting Phosphor for White LED," J. Lumin., vol.111, no.3, pp.139-145, 2005.

[3] Y. Hu, W. Zhuang, H. He, R. Liu, G. Chen, Y. Liu, and X. Huang, "High temperature stability of $\mathrm{Eu}^{2+}$ activated nitride red phosphors," J. Rare. Earths., vol.32, no.1, pp.12-16, 2014.

[4] F. Gándara, J. Perles, N. Snejko, M. Iglesias, B. Gómez-Lor, E. Gutiérrez-Puebla, and M.Á. Monge, "Layered Rare-Earth Hydroxides: A Class of Pillared Crystalline Compounds for Intercalation Chemistry," Angew. Chem., Int. Ed., vol.45, no.47, pp.7998-8001, 2006.

[5] A.M. Ajlouni, Z.A. Taha, K.A. Al-Hassan, and A.M.A. Anzeh, "Synthesis, characterization, luminescence properties and antioxidant activity of Ln complexes with a new aryl amide bridging ligand," J. Lumin., vol.132, no.6, pp.1357-1363, 2012.

[6] D.N. Woodruff, R.E.P. Winpenny, and R.A. Layfield, "Lanthanide Single-Molecule Magnets," Chem. Rev, vol.113, no.7, pp.5110-5148, 2013.

[7] L.J. Murray, M. Dincă, and J.R. Long, "Hydrogen storage in metal-organic frameworks," Chem. Soc. Rev., vol.38, no.5, pp.1294-1314, 2009.

[8] G.E. Buono-Core, H. Li, and B. Marciniak, "Quenching of Excited States by Lanthanide Ions and Chelates in Solution," Coordination Chemistry Reviews, vol.99, pp.55-87, 1990.

[9] T.-F. Liu, W. Zhang, W.-H. Sun, and R. Cao, "Conjugated Ligands Modulated Sandwich Structures and Luminescence Properties of Lanthanide Metal-Organic Frameworks," Inorg. Chem., vol.50, no.11, pp.5242-5248, 2011.

[10] P.R. Selvin and J.E. Hearst, "Luminescence energy transfer using a terbium chelate: improvements on fluorescence energy transfer,"
Proc. Natl. Acad. Sci. USA., vol.91, no.21, pp.10024-10028, 1994.

[11] M. Latva, H. Takalo, V.-M. Mukkala, C. Matachescu, J.C. Rodríguez-Ubis, and J. Kankare, "Correlation between the lowest triplet state energy level of the ligand and lanthanide(III) luminescence quantum yield," J. Lumin., vol.75, no.2, pp.149-169, 1997.

[12] X.-X. Li, Z.-Q. Wei, S.-T. Yue, N. Wang, H.-H. Mo, and Y.-L. Liu, "A New Lanthanide Coordination Polymer with 4,4'-Oxybis (Benzoic Acid) Lignad: Hydrothermal Synthesis, Crystal Structure and Photoluminescence," J. Chem., Crystallogr., vol.41, no.5, pp.757-761, 2011.

[13] J. Heine and K. Müller-Buschbaum, "Engineering metal-based luminescence in coordination polymers and metal-organic frameworks," Chem. Sov. Rev, vol.42, no.24, pp.9232-9242, 2013.

[14] P. Lenaerts, K. Driesen, R.V. Deun, and K. Binnemans, "Covalent Coupling of Luminescent Tris(2-thenoyltrifluoroacetonato)lanthanide(III) Complexes on a Merrifield Resin," Chem. Mater, vol.17, no.8, pp.2148-2154, 2005.

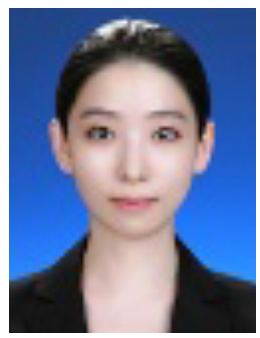

Seo Young Im received B.S., M.S. degrees in Chemistry from Sungkyunkwan University, Republic of Korea, in 2012, 2014, respectively. She is now working at HYOSUNG R\&D Business Labs., as a senior researcher about Organic/Inorganic Electronic Materials \& Device.

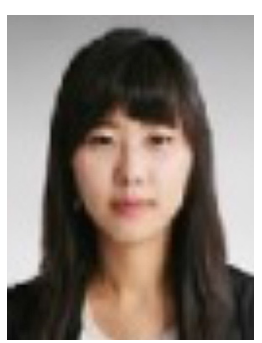
Da Hyeon Go received B.S., M.S. de-
grees in Chemistry from Kyunghee University, Republic of Korea, in 2007, 2009, respectively. She is now working at HYOSUNG R\&D Business Labs., as a principal researcher about Organic/Inorganic Electronic Materials \& Device.

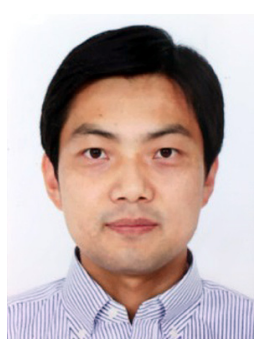

Jeong Gon Ryu received B.S., M.S. degrees in Material engineering from Sunchon National University, Republic of Korea, in 2001, 2003, respectively. He is now with HYOSUNG R\&D Business Labs., as chief researcher about Organic/Inorgnic Electronic Materials \& Device. 


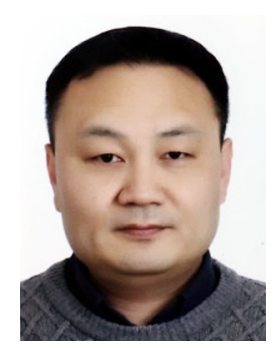

Young Sic Kim received B.S., M.S. degrees in Chemistry from Sungkyunkwan University, Republic of Korea, in 2000, 2002, respectively. He is now with HYOSUNG R\&D Business Labs., as a team manager about Organic/Inorganic Electronic Materials \& Device. 